\title{
Progressive atrioventricular conduction defects and heart failure in mice expressing a mutant Csx/Nkx2.5 homeoprotein
}

\author{
Hideko Kasahara, ${ }^{1}$ Hiroko Wakimoto, ${ }^{2}$ Margaret Liu, ${ }^{3}$ Colin T. Maguire, ${ }^{2}$ \\ Kimber L. Converso, ${ }^{1}$ Tetsuo Shioi, ${ }^{1}$ Weei-Yuarn Huang, ${ }^{1}$ Warren J. Manning, ${ }^{1}$ \\ David Paul, ${ }^{4}$ Joel Lawitts, ${ }^{5}$ Charles I. Berul, ${ }^{2}$ and Seigo Izumo ${ }^{1}$ \\ ${ }^{1}$ Cardiovascular Division, Beth Israel Deaconess Medical Center, Department of Medicine, and \\ ${ }^{2}$ Department of Cardiology, Children's Hospital, Department of Pediatrics, Harvard Medical School, \\ Boston, Massachusetts, USA \\ ${ }^{3}$ Department of Biology, University of Michigan, Ann Arbor, Michigan, USA \\ ${ }^{4}$ Department of Cell Biology, and \\ ${ }^{5}$ Transgenic Facility, Beth Israel Deaconess Medical Center, Department of Pathology, Harvard Medical School, \\ Boston, Massachusetts, USA \\ Address correspondence to: Hideko Kasahara, Beth Israel Deaconess Medical Center, \\ 330 Brookline Avenue SL215, Boston, Massachusetts 02215, USA. \\ Phone: (617) 667-4862; Fax: (617) 975-5268; E-mail: hkasahar@caregroup.harvard.edu.
}

Received for publication March 8, 2001, and accepted in revised form June 4, 2001.

\begin{abstract}
A DNA nonbinding mutant of the NK2 class homeoprotein Nkx2.5 dominantly inhibits cardiogenesis in Xenopus embryos, causing a small heart to develop or blocking heart formation entirely. Recently, ten heterozygous CSX/NKX2.5 homeoprotein mutations were identified in patients with congenital atrioventricular $(\mathrm{AV})$ conduction defects. All four missense mutations identified in the human homeodomain led to markedly reduced DNA binding. To examine the effect of a DNA binding-impaired mutant of mouse Csx/ $\mathrm{Nkx} 2.5$ in the embryonic heart, we generated transgenic mice expressing one such allele, I183P, under the $\beta$-myosin heavy chain promoter. Unexpectedly, transgenic mice were born apparently normal, but the accumulation of Csx/ $\mathrm{Nkx} 2.5$ (I183P) mutant protein in the embryo, neonate, and adult myocardium resulted in progressive and profound cardiac conduction defects and heart failure. P-R prolongation observed at 2 weeks of age rapidly progressed into complete AV block as early as 4 weeks of age. Expression of connexins 40 and 43 was dramatically decreased in the transgenic heart, which may contribute to the conduction defects in the transgenic mice. This transgenic mouse model may be useful in the study of the pathogenesis of cardiac dysfunction associated with CSX/NKX2.5 mutations in humans.
\end{abstract}

J. Clin. Invest. 108:189-201 (2001). DOI:10.1172/JCI200112694.

\section{Introduction}

The homeodomain-containing (HD-containing) transcription factors, characterized by their 60 -amino acid DNA-binding domain, play critical roles in developmental patterning and differentiation. Csx/Nkx2.5 is a member of the NK2-class HD protein, characterized by $\mathrm{Tyr}^{54}$ in the HD. Most of the NK2-class HD proteins are expressed in a tissue-specific manner, suggesting their role in tissue specification and development. Csx/ $\mathrm{Nkx} 2.5$ has been characterized as one of the earliest markers of the cardiac mesoderm from the fly to humans (1-9).

Recently, ten heterozygous mutations of human CSX/NKX2.5 were identified in patients with congenital heart disease $(10,11)$. These patients showed progressive atrio-ventricular (AV) conduction defects, isolated ventricular dysfunction, and various types of cardiac malformations $(10,11)$. Four mutations are single missense mutations in the HD that result in markedly reduced DNA binding but preserved homodimerization ability (12). Expression of a similar DNA- nonbinding mutant of Xenopus $\mathrm{Nkx} 2.5$ has been shown to cause a dominant inhibitory effect in Xenopus embryos, which showed small heart or no heart formation (13). To examine the effect of a DNA-nonbinding mutant of Csx/ Nkx2.5, Csx/Nkx2.5(I183P) (14), in the mammalian embryonic heart, we generated transgenic mice expressing Csx/Nkx2.5(I183P) mutant under the control of the $\beta$-myosin heavy chain ( $\beta$-MHC) promoter. Unexpectedly, mice expressing the mutant Csx/Nkx2.5 were born apparently normal, but the accumulation of Csx/ Nkx2.5(I183P) in the embryo, neonate, and adult myocardium resulted in progressive cardiac conduction defects and heart failure.

\section{Methods}

Animal models. Transgenic (TG) mice expressing Csx/ Nkx2.5(I183P) or wild-type Csx/ $\mathrm{Nkx} 2.5$ in the heart were created as follows. A cDNA encoding a FLAGtagged Csx $/ N k x 2.5(I 183 P)$ or Csx/Nkx2.5 in pMALC2 was digested with SacI and EcoRI, blunt ended, and lig- 
a
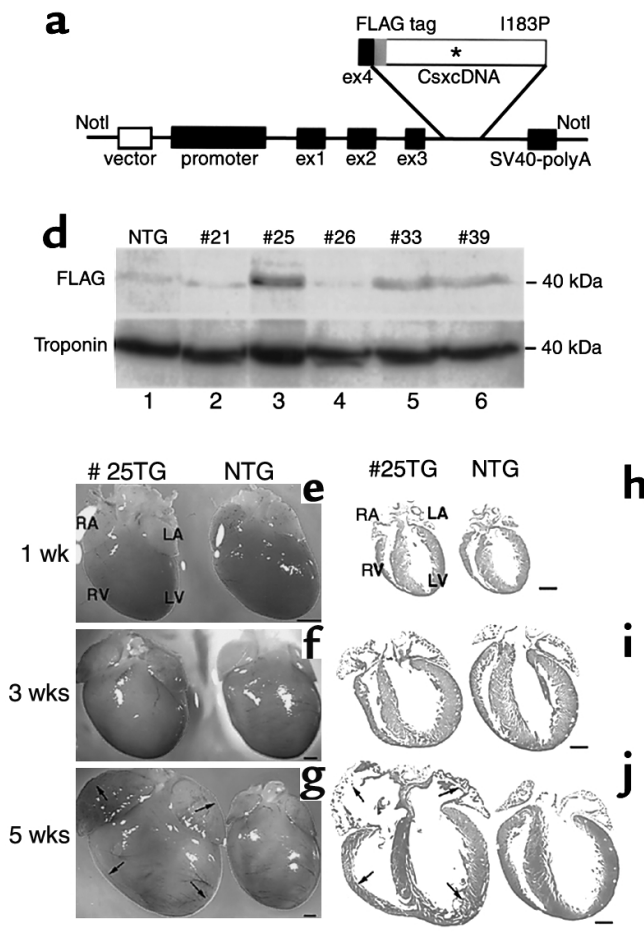

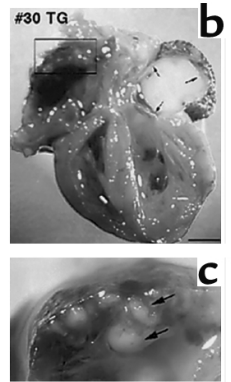

h

i j ated into SpeI-digested blunt-ended $\beta$-MHC promoter (a generous gift from J. Robbins) (15). NotI-digested plasmid was purified and injected into fertilized oocytes derived from FVB mice and were transferred into pseudopregnant mice. TG founders were identified by Southern blot analysis of tail DNA using SV40 poly(A) as a probe. Green fluorescent protein (GFP) (16) or FLAG-tagged dominant negative H-Ras(N17) (T. Shioi and S. Izumo, unpublished data) expressing TG mice were generated using $\alpha$-MHC promoter (a generous gift from J. Robbins) (17). Myocardial infarction was created in female FVB mice (approximately 3 months of age; 25-30 g of body weight) by left coronary artery ligation. Values for heart failure in sham-operated, two moderate, and two severe heart failure mice are as follows: mean heart weight/body weight ratio, $4.22 \pm 0.303$ vs. $5.41 \pm$ 0.354 vs. $9.51 \pm 1.33 \mathrm{mg} / \mathrm{g}$, respectively; mean heart weight/tibial length, $5.83 \pm 0.207$ vs. $7.97 \pm 0.935$ vs. 14.6 $\pm 1.35 \mathrm{mg} / \mathrm{mm}$, respectively; mean $\mathrm{LV}$ end-diastric dimension, $3.46 \pm 0.023$ vs. $4.64 \pm 0.06$ vs. $5.72 \pm 0 \mathrm{~mm}$, respectively; mean LV end-systolic dimension, $1.89 \pm$ 0.113 vs. $3.22 \pm 0$ vs. $4.24 \pm 0.17 \mathrm{~mm}$, respectively; mean LV fractional shortening, $45 \pm 3.3$ vs. $31 \pm 0.5$ vs. $26 \pm$ $3.0 \%$, respectively. All aspects of animal care and experiments performed in this study were approved by the Institutional Animal Care and Use Committee of the Beth Israel Deaconess Medical Center.

Protein analysis, immunostaining, and histological analysis of the TG mice. Hearts dissected from TG mice embryos ( 14 days postcoital (dpc) and $17 \mathrm{dpc}$ ) were lysed directly in $100 \mu \mathrm{l}$ of SDS-sample buffer with sonication. Forty microliters of sample were separated on a $10 \%$ polyacrylamide gel and transferred to
PVDF membrane. Approximately $60 \mu \mathrm{g}$ of heart lysate extracted from $F_{1}$ neonates or $100 \mu \mathrm{g}$ of heart lysate from 3-week or 6-week-old nontransgenic (NTG) or TG mice were used for Western blot analysis. Diluted anti-FLAG polyclonal antibody (pAb) (50×; Zymed Laboratories Inc., South San Francisco, California, USA), diluted anti-FLAG mAb (200x; Sigma Chemical Co., St. Louis, Missouri, USA), supernatant of anti-Csx/Nkx2.5 mAb (18), diluted anti-connexin 40 pAb (200×; provided by D. Paul), anti-connexin $43 \mathrm{pAb}$ (provided by $\mathrm{D}$. Paul or by Zymed Laboratories Inc.), diluted anti-Troponin $\mathrm{T}$ mAb (50x; Sigma Chemical Co.), diluted antiGAPDH mAb (2,000×; Research Diagnostics Inc., Flanders, New Jersey, USA), and diluted anti-GFP pAb (100x; CLONTECH Laboratories Inc., Palo Alto, California, USA) were used for Western blot analysis. Immunohistochemistry and immunofluorescent studies were performed as described (18). Diluted anti-FLAG pAb (100×-200×; Zymed Laboratories Inc.), diluted anti-connexin 40 and $43 \mathrm{Ab}(50 \times)$, diluted antisarcomeric actinin (100x; Sigma Chemical Co.), and the supernatant of anti-Csx/Nkx2.5 mAb's (18) were used for immunohistochemistry and immunofluorescent studies. For histological analysis, tissues were fixed in $4 \%$ paraformaldehyde/PBS overnight, dehydrated, and embedded in paraffin and sectioned. Tissue sections were stained with hematoxylin/eosin or Masson's trichrome.

For electron microscopy, left ventricular walls from 8week-old mice were fixed in $2.5 \%$ glutaraldehyde and $100 \mathrm{mM}$ calcium cacodylate overnight, and postfixed with $1 \% \mathrm{OsO}_{4}$, stained en bloc with $2 \%$ uranyl acetate, 
a

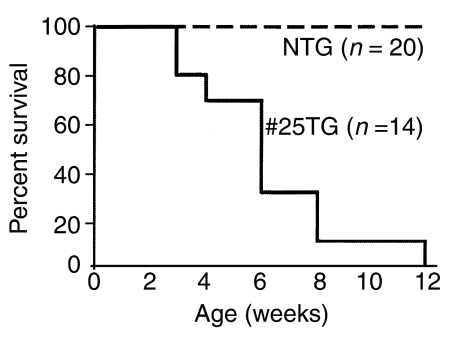

b

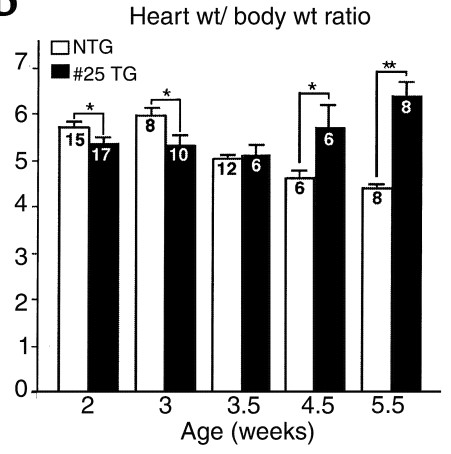

Figure 2

Analysis of heart failure. (a) Survival analysis of Csx/Nkx2.5(I183P) TG mice from line no. 25 mice. Heterozygous offspring were generated by crossing the TG male with NTG female. Percentage of survival of NTG mice $(n=20$; dotted line) and no. 25 TG mice ( $n=14$; continuous line). (b) Heart weight/body weight $(\mathrm{mg} / \mathrm{g})$ of NTG and TG from 2 weeks to 5.5 weeks of age. Heart weight/body weight was higher in NTG mice until 3 weeks of age, almost comparative at 3.5 weeks, but was significantly increased in the TG heart at 4.5 weeks, and was further increased at 5.5 weeks. The number of mice examined is indicated in each bar. ${ }^{*} P<0.05$. embedded in Apon 812, sectioned, and stained with 4\% uranyl acetate/Reynold's lead citrate. Thin sections were examined using a Zeol 100 CX electron microscope.

Echocardiogram and electrophysiological analysis. Echocardiographic examination of mice was performed as described (19). Briefly, mice were anesthetized with chloral hydrate $(0.4 \mathrm{mg} / \mathrm{g}$ intraperitoneally), and M-mode recordings of the left ventricle were obtained at the level of the papillary muscles from a parasternal window using a Hewlett-Packard (Andover, Massachusetts, USA) Sonos 5500 equipped with a $12-\mathrm{MHz}$ probe. Electrocardiogram (ECG) acquisition was performed as described $(20,21)$. Briefly, mice anesthetized with chloral hydrate $(0.4 \mathrm{mg} / \mathrm{g})$ by intraperitoneal injection were analyzed by multilead-surface ECG. ECG recordings were acquired on a multichannel amplifier and converted to a digital signal for analysis (MACLab system; AD Instruments, Milford, Massachusetts, USA). Corrected QT interval was calculated using Mitchell's formula (22).

Northern and Southern blot analyses. Northern and Southern blot analyses were performed using conventional methods. The following probes were used: connexin 40 probe, connexin 40 PCR product-amplified primers (F: 5'-AAGCTAAAGAGGCCCACCGCACTG-3', R: $5^{\prime}$-TTCCGGGAGCCCATGTTATTACTG-3'); connexin 43 probe, BamHI- and NotI-digested connexin 43 A clone (provided by M. Deans); Csx/Nkx2.5 probe, SacII-EcoNI fragment of Csx/Nkx2.5 cDNA; connexin 43 probe, BamHI- and NotI-digested connexin 43 A clone (provided by M. Deans); SV40 poly(A), SpeI-NotI fragment of $\mathrm{p} \beta \mathrm{MyHC}-5$ (provided by J. Robbins).

\section{Results}

Generation of TG mice expressing DNA-nonbinding mutant of $\mathrm{Cs} x / N k x 2.5$. We recently showed that $\mathrm{Csx} / \mathrm{Nkx} 2.5$ homodimerized and a single missense mutation $\left({ }^{183} \mathrm{Ile} \rightarrow\right.$ Pro: $\left.\mathrm{I183P}\right)$ in the third helix of the HD preserved homodimerization function, but totally abolished DNA binding (14). To examine the effect of the I183P mutant in vivo, TG mice were created expressing FLAG-tagged Csx/Nkx2.5(I183P) under the control of the 5.6-kb $\beta$-MHC promoter, which directs transgene expression predominantly in fetal ventricles (15) (Figure 1a). Six TG founders for Csx/Nkx2.5(I183P)-TG were identified after screening 28 founder mice (Table 1). One
TG founder (no. 30) died suddenly at 4 months of age. Necropsy showed enlargement of both atria and ventricles, with a large organized thrombus in the left atrium and many small thrombi in the right atrium (Figure 1, b and c), indicative of chronic biventricular heart failure.

Five other TG founder mice (nos. 21, 25, 26, 33, and 39) survived to generate TG-positive offspring. As shown in Figure 1d, mutant protein was detected by anti-FLAG $\mathrm{Ab}$ in lines nos. 25, 33, and 39, but was barely detectable in line 21 and 26 at the newborn stage. The no. 25 founder died at 6 months of age with heart failure similar to the no. 30 mouse. The heterozygous offspring of no. 25 TG mice were used for further analysis of Csx/Nkx2.5(I183P)-TG.

The hearts of Csx/Nkx2.5(I183P)-TG (line no. 25) mice were examined at 1,3 , and 5 weeks of age (Figure $1, \mathrm{e}-\mathrm{j})$. At 1 week of age, the heart appeared normal compared with NTG mice (Figure 1, e and h). At 3 weeks of age, the heart was slightly spherical compared with NTG (Figure 1, f and i) and rapidly progressed to four-chamber enlargement by 5 weeks of age (Figure 1, $\mathrm{g}$ and $\mathrm{j}$ ). Survival analysis indicates that most mice died before 12 weeks of age (Figure $2 \mathrm{a}$ ).

We measured heart weight at 2, 3, 3.5, 4.5, and 5.5 weeks normalized to body weight (heart weight/body weight ratio; Figure 2b) in Csx/Nkx2.5(I183P)-TG mice. The heart weight/body weight ratio was significantly higher in NTG mice until 3 weeks of age, comparable at 3.5 weeks of age, and significantly lower at 4.5 and 5.5 weeks of age. To address the functional consequences of I183P mutant expression in vivo, echocardiography was performed on 8-week-old Csx/Nkx2.5(I183P)-TG and

\section{Table 1}

$\beta-M H C-C s x / N k x 2.5(I 183 P)$ TG mice summary

\begin{tabular}{lcccc}
\hline $\begin{array}{l}\text { Rate of genotype } \\
\text { positive } F_{0} \text { mice }\end{array}$ & Line & $\begin{array}{c}\text { Germline } \\
\text { transmission }\end{array}$ & $\begin{array}{c}\text { Protein } \\
\text { expression }\end{array}$ & $\begin{array}{c}\text { Death before } \\
\text { months of ag }\end{array}$ \\
$21.4 \%(6 / 28)$ & No. 21 & + & \pm & - \\
& No. 25 & + & ++ & + \\
& No. 26 & + & - & - \\
& No. 30 & - & NA & + \\
& No. 33 & + & + & - \\
& No. 39 & + & + & - \\
\hline
\end{tabular}


NTG
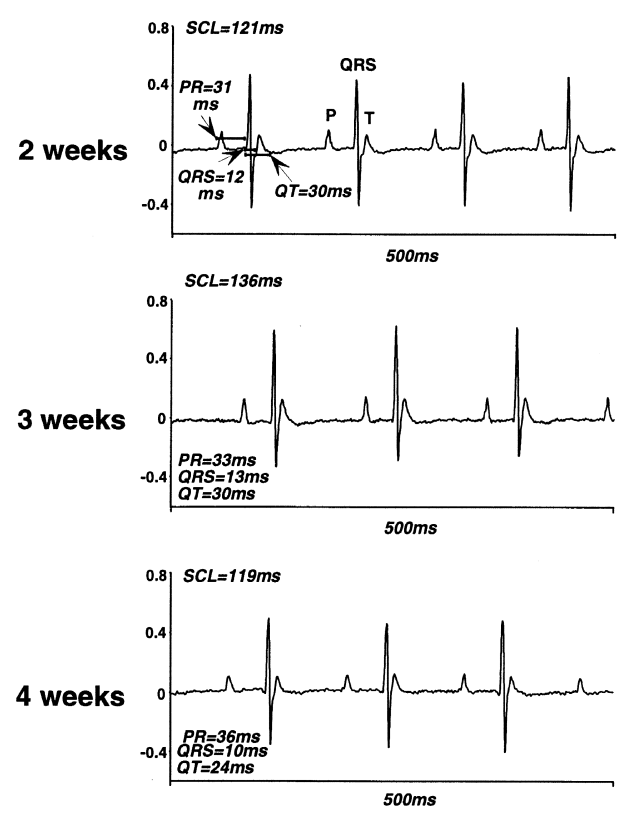

\#25TG
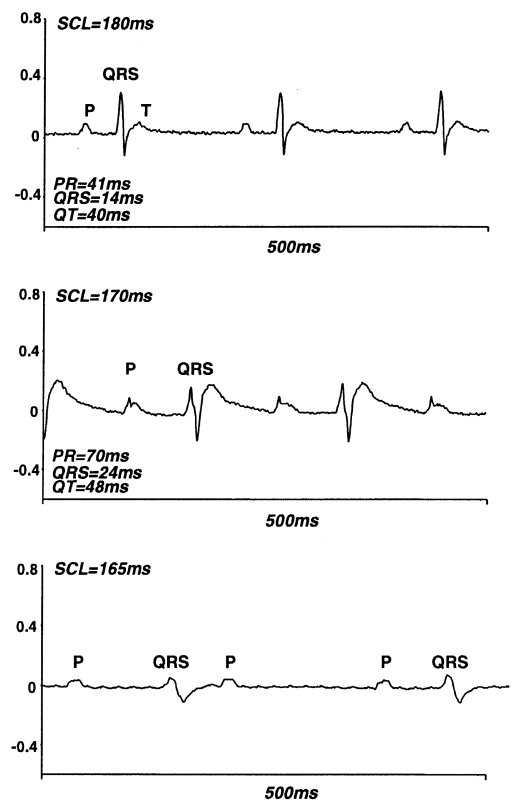

Figure 3

Selected surface ECG from TG mice 2, 3 , and 4 weeks old showed rapidly progressive conduction defects. At 2 weeks, NTG mice showed a regular ECG trace with P-QRS-T waves with SCL $121 \mathrm{~ms}(\mathrm{HR}=495 \mathrm{bpm})$, PR interval $31 \mathrm{~ms}$, QRS $12 \mathrm{~ms}$, QT $30 \mathrm{~ms}$. TG also showed regular P-QRS-T waves, with prolonged SCL $(180 \mathrm{~ms} ; \mathrm{HR}=$ 333), PR (41 ms), QRS (14 ms), and QT (40 ms) intervals. At 3 weeks, PR, $\mathrm{QRS}$, and QT intervals were markedly prolonged in TG mice. At 4 weeks of age, $\mathrm{P}$ and $\mathrm{QRS}$ waves were independently recorded (complete AV block) in TG mice. QRS voltage was progressively decreased from 2 weeks of age. See Tables 3 and 4.
NTG mice, which confirmed left-ventricular dilation and depressed left-ventricular systolic function in Csx/Nkx2.5(I183P)-TG mice (Table 2).

Thus, two TG mouse lines showed a heart failure phenotype (no. 25 and no. 30) among six transgenic lines (Table 1). The line that showed the progressive heart failure phenotype before 4 months of age (line no. 25) expressed a higher amount of the mutant protein than the other transgenic lines (lane 3, Figure 1d). None of the $F_{1}$ mice in line no. 33 or 39 , which expressed moderate levels of the mutant protein, died before 4 months of age (Table 1). However, female mice developed heart failure occasionally after pregnancy (data not shown). Profound conduction defects in no. 25 mice. ECGs were obtained on NTG and Csx/Nkx2.5(I183P)-TG mice (line no. 25) and analyzed for mean sinus-cycle length (SCL; beat-to-beat heart rate), heart rate (HR), P-R interval (atrial and A-V nodal conduction time), QRS interval (ventricular depolarization time), Q-T interval (a surrogate of action potential duration), and the rate-corrected Q-T interval (QTc) at 2, 3, and 4 weeks of age. As shown in Figure 3, Csx/Nkx2.5(I183P)-TG mice at 2 weeks of age exhibited first-degree AV block evidenced by the prolongation of PR interval (control $=31 \mathrm{~ms}$ vs. $\mathrm{TG}=41 \mathrm{~ms}$ ), accompanied by pro- longation of mean SCL (control $=121 \mathrm{~ms}$ vs. $\mathrm{TG}=180$ $\mathrm{ms}$ ) and prolongation of QRS and QT intervals. At 3 weeks of age, PR interval was further increased, and widening of QRS and QT interval was further apparent. At 4 weeks of age, Csx/Nkx2.5(I183P)-TG mice started to show complete AV block. A summary of data is shown in Table 3. In addition, QRS voltage was progressively diminished (Figure 3; QRS, NTG vs. TG, Table 4). This suggests that intraventricular conduction was also progressively disturbed in Csx/Nkx2.5(I183P)-TG mice (line no. 25). Of note, among five transgenic mice of line no. 33 examined, two mice showed prolonged PR interval (PR interval $=70 \mathrm{~ms} ; 54 \mathrm{~ms}$ vs. mean $42 \pm 5 \mathrm{~ms}$ in NTG; $n=11$ ) and three showed normal PR intervals at the age of 12 weeks.

Downregulation of the gap junction protein connexin 43 in the Csx/Nkx2.5(I183P)-TG heart. The propagation of electrical activity in the myocardium depends on the intercellular transfer of current at gap junctions. In cardiomyocytes, connexin 43 is the most abundant gap junction protein (23). Therefore, we examined connexin $43 \mathrm{mRNA}$ levels by Northern blot analysis in hearts from NTG and Csx/Nkx2.5(I183P)-TG mice (line no. 25 ) between the neonatal stage and 3 weeks of age. In Csx/Nkx2.5(I183P)-TG heart, connexin 43 expression

Table 2

Echocardiographic indices of Csx/Nkx2.5(I183P)-TG no. 25

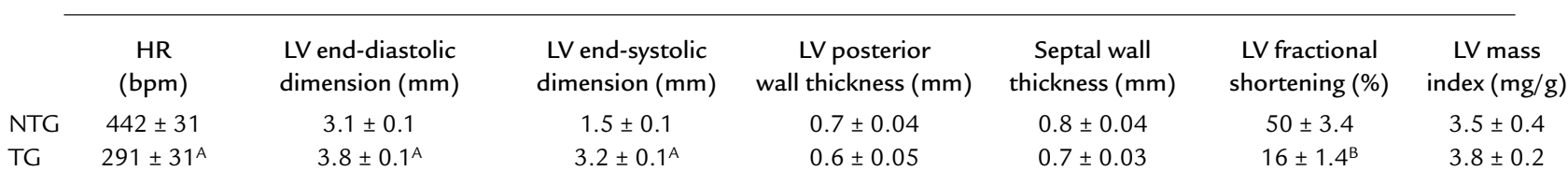

Values are expressed as mean \pm SEM. ${ }^{A} P<0.01,{ }^{B} P<0.0001$ compared with age- and sex-matched NTG. 


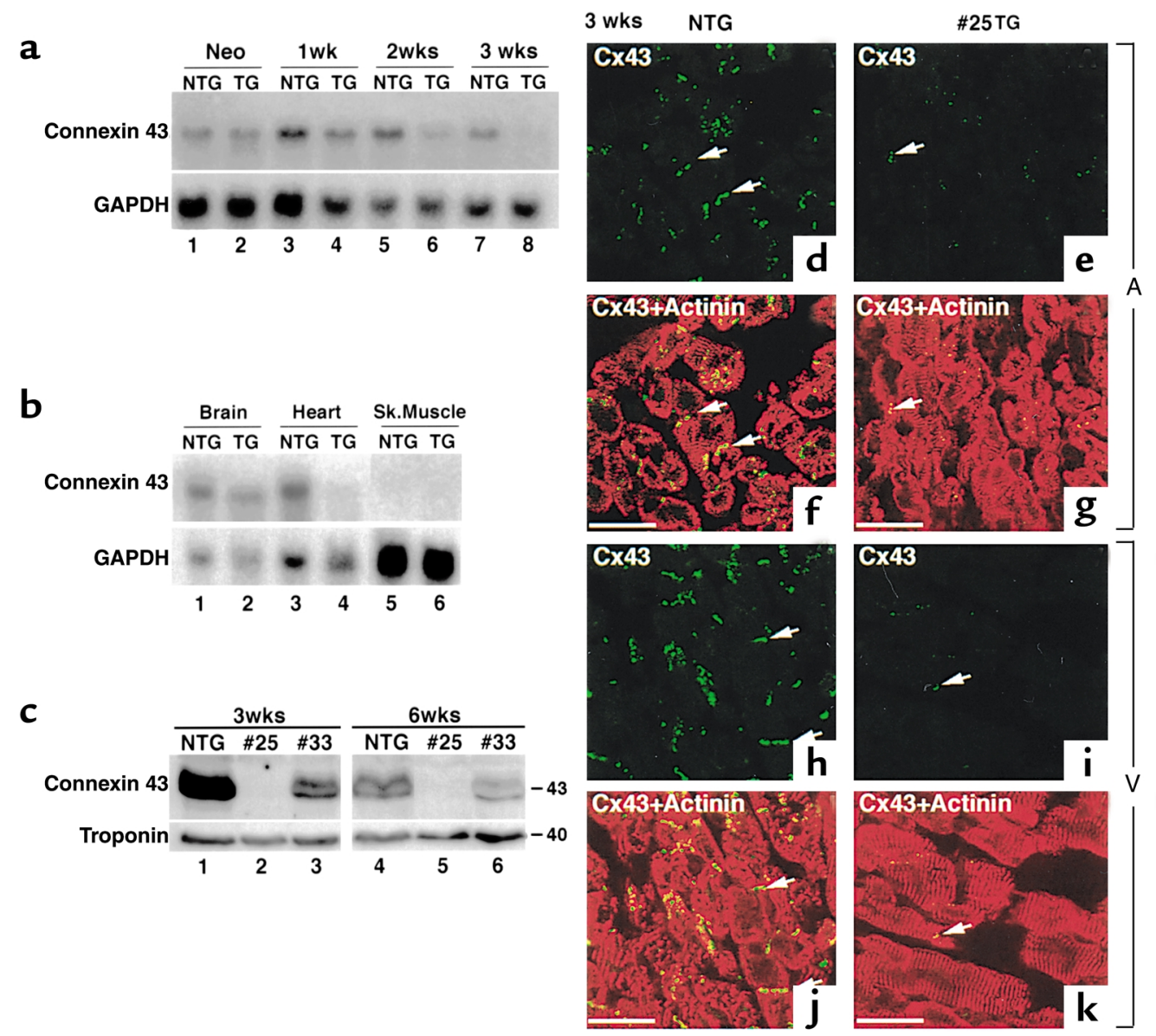

\section{Figure 4}

Reduced expression of connexin 43 in the TG heart. (a) Northern blot analysis of connexin 43 from neonatal stage to 3 weeks of age. Connexin 43 mRNA expression was similar between NTG (lane 1) and TG (lane 2) at the neonatal stage, but gradually decreased in the TG mouse heart (compare lane 3 vs. 4 , lane 5 vs. 6, and lane 7 vs. 8). Connexin 43 transcript in TG mice was barely detectable at 3 weeks of age (lane 8). GAPDH expression is also shown. (b) Connexin 43 downregulation was heart specific. Northern blot analysis of connexin 43 in brain, heart, and skeletal muscle. GAPDH expression is also shown. (c) Western blot analysis of connexin 43 in the TG ventricle at 3 and 6 weeks from two different TG lines (numbers 25 and 33), compared with NTG ventricles. Connexin 43 protein expression was markedly reduced in no. 25 line and moderately reduced in no. 33 line. Troponin T expression was also shown. (d-k) Immunofluorescent staining of connexin 43 (FITC) and sarcomeric actinin (rhodamine; merged image in $\mathbf{f}, \mathbf{g}, \mathbf{j}, \mathbf{k})$ in atrium ( $\mathrm{A} ; \mathbf{d}-\mathbf{g})$ and ventricle $(\mathrm{V} ; \mathbf{h}-\mathbf{k})$ at 3 weeks, and neonates of NTG and TG mice. (d and f) Connexin 43 staining (FITC) was observed in the NTG atrium (arrows) localized in cell-cell junctions, whereas connexin 43 expression in the TG atrium was occasionally detectable (e and $\mathbf{g}$ ). Note ventricular expression of connexin 43 (FITC) in NTC heart (h and $\mathbf{j}$ ) compared with TG heart (i and $\mathbf{k}$ ). Bars, $50 \mu \mathrm{m}$.

was apparently normal at the neonatal stage (Figure 4a; connexin 43, lane 1 vs. lane 2) and was gradually decreased to barely detectable levels at 3 weeks of age (Figure 4a; connexin 43, compare lanes 1, 3, 5, and 7 vs. lanes $2,4,6$, and 8 ). In contrast, the expression of connexin 43 in the brain of Csx/Nkx2.5(I183P)-TG mice was similar to NTG (Figure 4b, lane 1 vs. 2), indicating that the downregulation of connexin 43 expression in Csx/Nkx2.5(I183P)-TG mice is cardiac specific.

Connexin 43 protein expression was detected by Western blot analysis in NTG ventricles at 3 weeks of age (Figure 4c, lane 1). In contrast, it was barely detectable in no. 25 mice (Figure 4c, lane 2) and was significantly decreased in no. 33 mice (Figure 4c, lane 3), which expressed I183P mutant protein at a moderate level (Figure 1d). Similar results were observed at 6 weeks of age (Figure 4c, lanes 4-6). Immunofluorescent staining for connexin 43 (Figure 4, d-k; FITC) and antisarcomeric actinin (Figure 4, d-k; rhodamine) showed connexin 43 expression at the cell junctions in the atrium (Figure 4, d and f) and the ventricle (Figure 4, h and j) of NTG mice (3 weeks old). In contrast, connexin 43 expression was barely detectable in Csx/Nkx2.5(I183P)TG (line no. 25) heart (Figure 4, e, g, i, and k). These results indicate that connexin 43 expression was progressively decreased in the first 3 weeks after birth and was well-correlated to the progressive ECG changes in Csx/Nkx2.5(I183P)-TG heart (Figure 3).

Downregulation of connexin 40 in TG heart. We also examined the expression of connexin 40, which is expressed specifically in the conduction system (23-26). Connexin $40 \mathrm{mRNA}$ expression levels in the 
neonatal heart were relatively abundant and similar between NTG and Csx/Nkx2.5(I183P)-TG (line no. 25) (Figure 5a, lane 1 vs. 2). At 3 weeks of age, connexin 40 mRNA expression was below the level of detection when both atrial and ventricular RNA were used (data not shown). In atria, connexin 40 mRNA was relatively abundant in NTG, which was markedly reduced in Csx/Nkx2.5(I183P)-TG (Figure 5a, lane 3 vs. 4). Protein expression of connexin 40 in atrial lysates was similar between NTG and Csx/Nkx2.5(I183P)-TG at the neonatal stage but was also markedly downregulated at 2 and 3 weeks in TG (Figure 5b).

Immunofluorescent staining showed connexin 40 expression in the atrium (Figure 5, c and d), top of the intraventricular septum (IVS), which is most likely the $\mathrm{AV}$ node (Figure 5, e and $\mathrm{f}$ ), and in the ventricular myocardium adjacent to endocardium (which is most likely Purkinje fiber) (Figure 5, g and h). Expression of connexin 40 was comparable between the NTG and Csx/Nkx2.5(I183P)-TG (line no. 25) heart in the neonatal stage. At 3 weeks of age, connexin 40 expression in the NTG hearts was detected in the atrium (Figure 5, i and $\mathrm{k}$ ) and Purkinje fibers (Figure $5, \mathrm{~m}$ and $\mathrm{o}$ ), but was markedly decreased in the Csx/Nkx2.5(I183P)-TG heart (Figure 5, j, l, n, and p). Taken together, the expression of two major connexins, connexin 40 and 43 , was dramatically decreased in Csx/Nkx2.5(I183P)TG within 3 weeks after birth.

Histopathological analysis of the failing heart and the disturbed gap junction formation. To examine whether
Csx/Nkx2.5(I183P)-TG (line no. 25) mice develop specific histopathological changes, light microscopic analyses of hematoxylin/eosin-stained heart sections at 3 and 5 weeks of age were performed (Figure 6, a-d). At 3 weeks, no apparent differences between NTG and Csx/Nkx2.5(I183P)-TG hearts in myofibrillar organization, nuclear shape, and interstitial space were observed (Figure 6; 3 weeks, a and b). At 5 weeks, degenerated cardiomyocytes with myofibrillar disorganization and abnormally shaped nuclei were observed in Csx/Nkx2.5(I183P)-TG hearts (Figure 6; 5 weeks, c vs. d). Interstitial space was significantly increased with mild fibrosis detected by Masson's trichrome staining without apparent infiltration of inflammatory cells (Figure 6, e vs. f). These results demonstrate that the histopathological abnormalities were not evident at 3 weeks of age, but were apparent at 5 weeks of age.

We further examined Csx/Nkx2.5(I183P)-TG (line no. 25) hearts using thin-section electron microscopy (EM) (Figure 6, g-p). Electron density was decreased in Csx/Nkx2.5(I183P)-TG ventricles, presumably due to myofibrillar disorganization, a diminished filament density, and swelling of the mitochondria (Figure 6 , g vs. h). Each sarcomere unit was normally organized with distinct A- and I- bands, and Z- and Mlines (Figure 6, i vs. j). Intercalated discs situated at the site of vertical plicate regions of intercellular junctions were also normally organized in the Csx/Nkx2.5(I183P)-TG heart (Figure 6, k vs. 1). However, mitochondria were swollen and mitochondrial $\mathbf{a}$
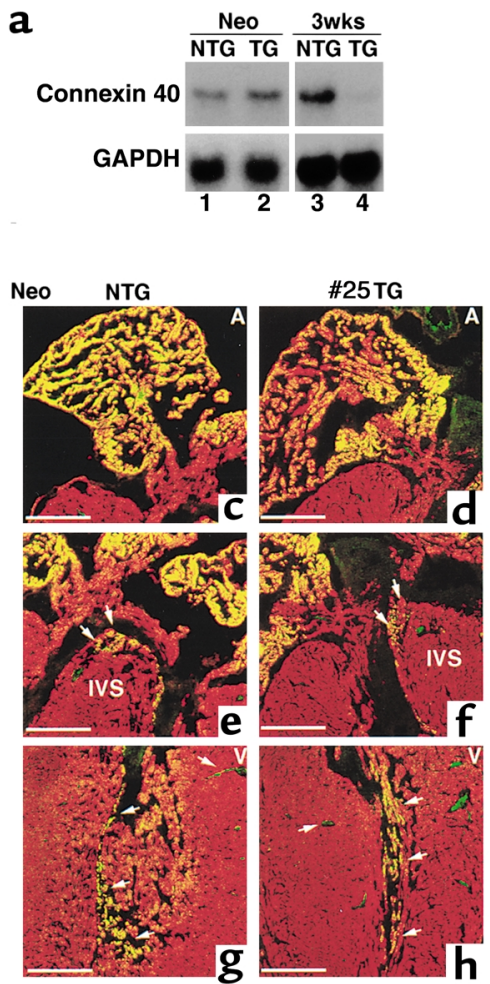

b
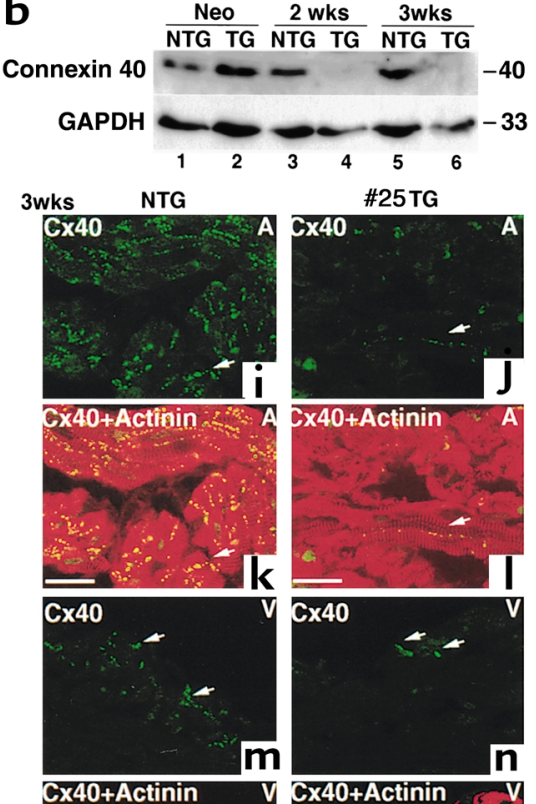

Cx40+Actinin

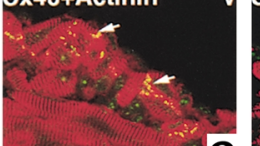

\section{Figure 5}

Reduced expression of connexin 40 in TG heart. (a) Northern blot analysis of connexin 40 in neonates (lanes 1 and 2) and mice 3 weeks of age (lanes 3 and 4). Connexin 40 mRNA expression is similar between NTG (lane 1) and TG (lane 2) at the neonatal stage, but was barely detectable in the TG heart at 3 weeks of age (lane 4), compared with the NTG heart (lane 3). RNA was extracted from the whole neonatal heart and from the atria of 3-weekold mice. GAPDH expression is also shown. (b) Western blot of connexin 40 for atria at neonates (lanes 1 and 2), and at 2 weeks (lanes 3 and 4 ) and 3 weeks of age (lanes 5 and 6). Connexin 40 protein expression in TG atria is markedly reduced at 2 weeks (lane 4) and 3 weeks of age (lane 6). (c-h) Immunofluorescent staining of connexin 40 (FITC) and sarcomeric actinin (rhodamine) on the neonatal heart. Only merged images are shown. Connexin 40 was expressed in atria (c and $\mathbf{d})$, intraventricular septum (IVS; $\mathbf{e}$ and $\mathbf{f}$ ), and Purkinje fiber in the ventricle ( $\mathbf{g}$ and $\mathbf{h}$ ). Bars, $300 \mu \mathrm{m}$. (i-p) Connexin 40 (FITC) and sarcomeric actinin (rhodamine) staining of 3-week-old NTG (i, $\mathbf{k}, \mathbf{m}$, and $\mathbf{o}$ ) and TG heart (j, I, n, and $\mathbf{p}$ ). Connexin 40 (FITC) was observed in NTG atrium (arrows) localized in cell-cell junctions, whereas connexin 40 expression in TG atrium was occasionally detectable ( $\mathrm{j}$ and $\mathbf{I}$ ). Ventricular expression of connexin 40 (FITC) in NTG heart ( $\mathbf{m}$ and $\mathbf{o}$ ) compared with TG heart ( $\mathbf{n}$ and $\mathbf{p})$. Bars, $50 \mu \mathrm{m}$. 

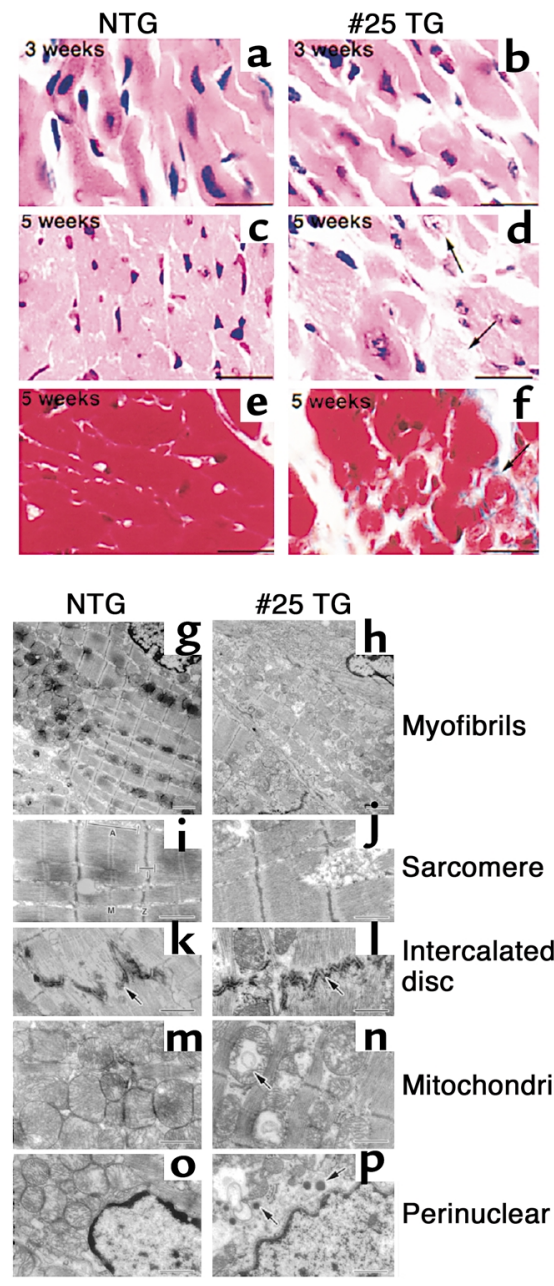
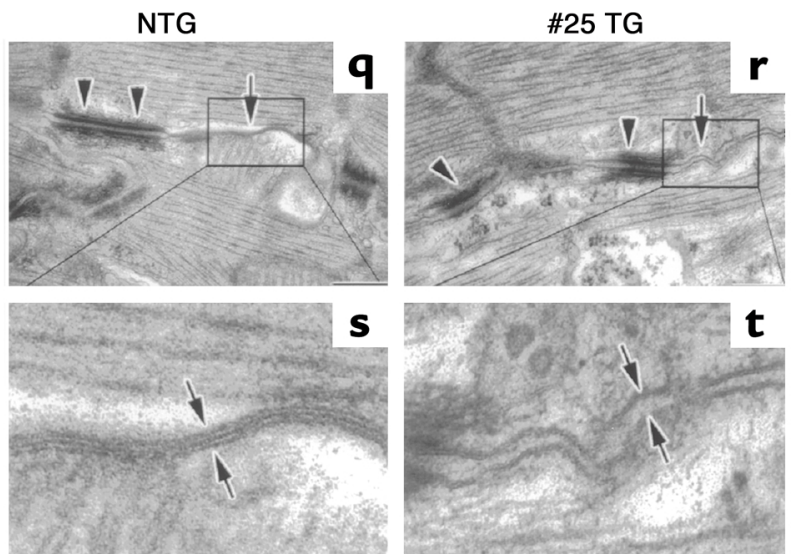

\section{Figure 6}

Histopathological analysis of heart failure. (a-f) Heart sections from 3- and 5-week-old mice stained with hematoxylin/eosin (a-d) and Masson's trichrome (e and $\mathbf{f}$ ). Hematoxylin/eosin-stained sections showed no apparent differences in 3-week-old TG mouse heart (b) and NTG (a). Degenerated cardiomyocytes evidenced by swelling of nucleus and myofibrils (arrows in d) were detected at 5 weeks of age. Intercellular space of TG heart is wider than NTG heart (d). Masson's trichrome-stained heart sections were obtained from NTG (e) and TG (f). Arrowheads (f) point to interstitial fibrosis (blue). Bars, $50 \mu \mathrm{m}$. (g-p) Electron micrographs of the left ventricles from NTG $(\mathbf{g}, \mathbf{i}, \mathbf{k}, \mathbf{m}$, and $\mathbf{o})$ mice and TG $(\mathbf{h}, \mathbf{j}$, $\mathbf{I}, \mathbf{n}$, and $\mathbf{p}$ ) at 8 weeks of age. ( $\mathbf{g}$ and $\mathbf{h}$ ) Myofibrils of the TG heart were sparsely distributed compared with NTG heart. Sarcomere (i and $\mathbf{j}$ ) and intercalated discs ( $\mathbf{k}$ and $\mathbf{I}$ ) were well-organized in the TG hearts similar to the NTG heart. Mitochondria were swollen and mitochondrial cristae were slightly broken. Mitochondria showed oval structures suggestive of mitochondrial deformation ( $\mathbf{m}$ and $\mathbf{n}$ ). The location of electron-dense small vesicles were perinuclear as well as cytoplasmic (p). Bars, $1.66 \mu \mathrm{m}$ in $\mathbf{g}$ and $\mathbf{h} ; 0.97 \mu \mathrm{m}$ in $\mathbf{i}-\mathbf{p}$. (q-t) The longitudinal zones of the intercellular junction occupied by desmosome (arrowheads) and gap junction (arrows) in NTG ( $\mathbf{q}$ and $\mathbf{s}$ ) and TG heart ( $\mathbf{r}$ and $\mathbf{t})$. Higher magnification of gap junction in NTG heart demonstrates three electron-dense lines indicating two membranes contacting at the middle (s). In the TG heart, intercellular contact at the gap junction was barely detected $(\mathbf{t})$. Bars, $0.15 \mu \mathrm{m}$. cristae were slightly broken (Figure 6, m vs. n). Abnormal oval structures in the mitochondria were detected frequently (Figure 6n, arrow). In addition, we detected electron-dense small vesicles located in the perinuclear region as well as in the cytoplasm, which may be atrial natriuretic factor-containing (ANF-containing) granules (Figure 6, o vs. p).

Higher magnification showed the gap junction (Figure 6, q-t, arrows) and desmosome (Figure 6, q-t, arrowheads) localized at the longitudinal zones of the intercellular junction in the NTG heart (27). In the Csx/Nkx2.5(I183P)-TG heart, cell-to-cell junctions formed by desmosome (arrowheads in Figure 6r) were easily found, but the tightly bound gap junction structure was barely evident (arrow in Figure 6r). Higher magnification of NTG heart clearly showed that two membranes were attached at gap junctions, resulting in the formation of the electron dense line between the two adjacent plasma membranes (Figure $6 \mathrm{~s})$. In contrast, in Csx/Nkx2.5(I183P)-TG hearts the two adjacent membranes were clearly separated (Figure $6 \mathrm{t}$ ). The EM images are consistent with a defect of gap junction formation in Csx/Nkx2.5(I183P)-TG hearts, presumably due to a very low level of expression of connexin 43 .
Mutant protein was expressed from embryonic stage through adult stage. We used the $\beta$-MHC promoter to drive transgene expression of Csx/ $\mathrm{Nkx} 2.5(\mathrm{I} 183 \mathrm{P})$. $\beta$ MHC is downregulated shortly after birth $(15,28,29)$. Thus, postnatal heart failure and massive conduction defects in Csx/Nkx2.5(I183P)-TG mice was unexpected. We examined the expression of mutant protein in line no. 25 mice at embryonic $(15 \mathrm{dpc})$, neonatal (day 1) and adult (4 weeks old) stages by immunohistochemistry using anti-FLAG Ab counterstained with methyl green for nuclear staining (Figure 7a). In the atrium, Csx $/ \mathrm{Nkx} 2.5(\mathrm{I} 183 \mathrm{P})$ protein was detected in heterologous pattern from the embryonic stage through adulthood (no. 25-A). Csx/Nkx2.5(I183P) protein was expressed more uniformly in the ventricle (no. 25-V) from the embryonic to the adult stage, which was mostly colocalized with the endogenous Csx/Nkx2.5 (Figure 7, b-g).

The expression levels of both mutant and endogenous $\mathrm{Csx} / \mathrm{Nkx} 2.5$ were determined in heart lysates from the Csx/Nkx2.5(I183P)-TG and NTG embryos at $14 \mathrm{dpc}$ (Figure 7h, lanes 1 and 2) and $17 \mathrm{dpc}$ (Figure 7h, lanes 3 and 4). Immunoblotting with anti-FLAG $A b$ detected the mutant protein around $40 \mathrm{kDa}$ as the doublet bands likely due to different phosphorylation 
Table 3

Electrocardiographic data of Csx/Nkx2.5(I183P)-TG no. 25 summary 1

\begin{tabular}{|c|c|c|c|c|c|c|c|}
\hline & & $\mathrm{SCL}(\mathrm{ms})$ & $\mathrm{HR}(\mathrm{bpm})$ & $\mathrm{PR}(\mathrm{ms})$ & $\mathrm{QRS}(\mathrm{ms})$ & $\mathrm{QT}(\mathrm{ms})$ & $\mathrm{QTc}(\mathrm{ms})$ \\
\hline \multirow[t]{2}{*}{2 weeks } & NTG $(n=6)$ & $128 \pm 11$ & $472 \pm 42$ & $37 \pm 6$ & $11 \pm 1$ & $33 \pm 2$ & $29 \pm 2$ \\
\hline & $\operatorname{TG}(n=6)$ & $160 \pm 12^{B}$ & $378 \pm 29^{B}$ & $47 \pm 7^{A}$ & $15 \pm 2^{B}$ & $47 \pm 6^{B}$ & $37 \pm 5^{B}$ \\
\hline \multirow[t]{2}{*}{3 weeks } & NTG $(n=10)$ & $125 \pm 16$ & $487 \pm 62$ & $32 \pm 5$ & $11 \pm 1$ & $30 \pm 2$ & $27 \pm 2$ \\
\hline & TG $(n=10)$ & $159 \pm 30^{B}$ & $389 \pm 71^{B}$ & $47 \pm 11^{B}$ & $19 \pm 4^{\mathrm{B}}$ & $50 \pm 7^{B}$ & $40 \pm 5^{B}$ \\
\hline
\end{tabular}

Values are expressed as mean $\pm \mathrm{SD} .{ }^{A} P<0.05,{ }^{\mathrm{B}} P<0.01$ compared with age- and sex-matched NTG.

states of Csx/Nkx2.5 (30) (Figure 7h; FLAG, lanes 2 and 4). Anti-Csx/Nkx2.5 mAb detected endogenous Csx/Nkx2.5 (Csx/Nkx2.5; lanes 1 and 3 ) as well as endogenous plus mutant protein in the Csx/Nkx2.5(I183P)-TG heart (Csx/Nkx2.5; lanes 2 and 4). The protein expression level was a few fold higher in Csx/Nkx2.5(I183P)-TG heart than NTG hearts during the embryonic stages when $\beta$-MHC promoter is most active (31). Of note, the epitope of Csx/ Nkx2.5 $\mathrm{mAb}$ is located outside the HD, thus both endogenous and mutant proteins are expected to be recognized by the $\mathrm{mAb}$ with the same affinity.

At the neonatal stage, we detected the mutant protein as shown in Figure 1d. Endogenous Csx/Nkx2.5 (Figure $7 \mathrm{i}$, lane 1) as well as endogenous plus mutant protein in Csx/Nkx2.5(I183P)-TG heart (Figure 7i, lane 2) were detected by anti-Csx/Nkx2.5 mAb. At 3 and 6 weeks of age, endogenous Csx/Nkx2.5 was not detected in the total heart lysate of the NTG heart (Figure 7i, lanes 3 and 5), but endogenous plus I183P mutant protein was detected in Csx/Nkx2.5(I183P)-TG heart lysate (Figure 7i, lanes 4 and 6).

Since the endogenous Csx/Nkx2.5 vs. I183P mutant proteins could not be distinguished by Western blot analysis, we performed Northern blot analysis to compare the transcript level. The probe (the carboxyl-terminus of the coding region of Csx/ $\mathrm{Nkx} 2.5$ ) hybridized to a region common to both endogenous and mutant $\mathrm{Csx} / \mathrm{Nkx} 2.5$. At the neonatal stage, we detected a major single band in NTG heart (Figure $7 \mathrm{j}$; $\mathrm{Csx} / \mathrm{Nkx} 2.5$, lane 1) and two bands in Csx/Nkx2.5(I183P)-TG heart (Figure 7i; Csx/Nkx2.5, lane 2$)$. The higher band also hybridized with the SV40 poly(A) probe (Figure 7j, SV40 pA in lane 2; see Figure 1a), and represents the mutant transcript. Similarly, two bands were detected in Csx/Nkx2.5(I183P)-
TG heart from neonatal to 3 weeks of age (Figure $7 \mathrm{j}$; Csx/Nkx2.5, lanes 2, 4, 6, and 8). The transcript level of the I183P mutant was approximately twice that of the endogenous Csx/Nkx2.5 in age-matched NTG in the neonatal heart (Figure 7j; Csx/Nkx2.5, compare lane 1 and slower migrating band in lane 2) and was two- to threefold that of the endogenous Csx/ Nkx2.5 in age-matched NTG at 1, 2, and 3 weeks of age (Figure 7j; Csx/Nkx2.5, lanes 3-8). Unexpectedly, we noted an upregulation of endogenous Csx/ Nkx2.5 expression in Csx/Nkx2.5(I183P)-TG hearts from the neonatal stage through 3 weeks of age (Figure $7 \mathrm{j}$; endogenous Csx/ $\mathrm{Nkx} 2.5$, lane 1 vs. 2 , lane 3 vs. 4, lane 5 vs. 6 , lane 7 vs. 8 ).

Connexin 43 expression in other heart failure mouse models. To investigate whether heart failure alone is sufficient for connexin 43 downregulation, we examined two other transgenic models exhibiting heart failure: overexpression of GFP, which we reported previously caused dilated cardiomyopathy (16) and overexpression of a dominant negative Ras(N17) (T. Shioi and S. Izumo, unpublished data). Increased heart weight/body weight was observed in both TG mice [6.9 $\mathrm{mg} / \mathrm{g}$ in GFP-TG (see ref. 16), $7.7 \mathrm{mg} / \mathrm{g}$ in Ras(N17)-TG vs. $4.1 \mathrm{mg} / \mathrm{g}$ in NTG]. Connexin 43 expression appeared to be moderately downregulated in GFP-TG (Figure 8b), but not in Ras(N17)-TG (Figure 8c). GFPTG showed additional green fluorescent signals in both cytosol and nuclei (Figure 8b).

SDS-PAGE of heart lysates from GFP-TG, Ras(N17)TG and Csx/Nkx2.5(I183P)-TG (line no. 25) mice stained with Coomassie blue showed the 29-kDa GFP band in GFP-TG (Figure 8d, lane 2). Western blot analysis confirmed a significant decrease of connexin 43 expression in GFP-TG, but it was modest compared with the decrease observed in Csx/Nkx2.5(I183P)-TG

Table 4

Electrocardiographic data of Csx/Nkx2.5(I183P)-TG no. 25 summary 2 (voltage and axis)

\begin{tabular}{|c|c|c|c|c|c|c|c|}
\hline & & Voltage L1 & L2 & L3 & aVR & $\mathrm{aVL}$ & aVF \\
\hline \multirow[t]{2}{*}{2 weeks } & NTG $(n=6)$ & $796 \pm 202$ & $2,555 \pm 494$ & $2,280 \pm 509$ & $1,562 \pm 183$ & $1,230 \pm 259$ & $1,882 \pm 791$ \\
\hline & $\mathrm{TG}(n=6)$ & $347 \pm 157^{B}$ & $1,065 \pm 176^{\mathrm{B}}$ & $935 \pm 222^{B}$ & $661 \pm 149^{B}$ & $472 \pm 151^{A}$ & $992 \pm 185^{A}$ \\
\hline \multirow[t]{2}{*}{3 weeks } & $\operatorname{NTG}(n=10)$ & $1,585 \pm 855$ & $2,133 \pm 293$ & $1,540 \pm 655$ & $1,645 \pm 424$ & $1,129 \pm 771$ & $1,785 \pm 401$ \\
\hline & TG $(n=11)$ & $402 \pm 322^{B}$ & $796 \pm 197^{B}$ & $670 \pm 147^{B}$ & $528 \pm 213^{B}$ & $351 \pm 91^{B}$ & $708 \pm 158^{B}$ \\
\hline
\end{tabular}

Values are expressed as mean \pm SD. ${ }^{A} P<0.05,{ }^{B} P<0.01$ compared with age- and sex-matched NTG. 

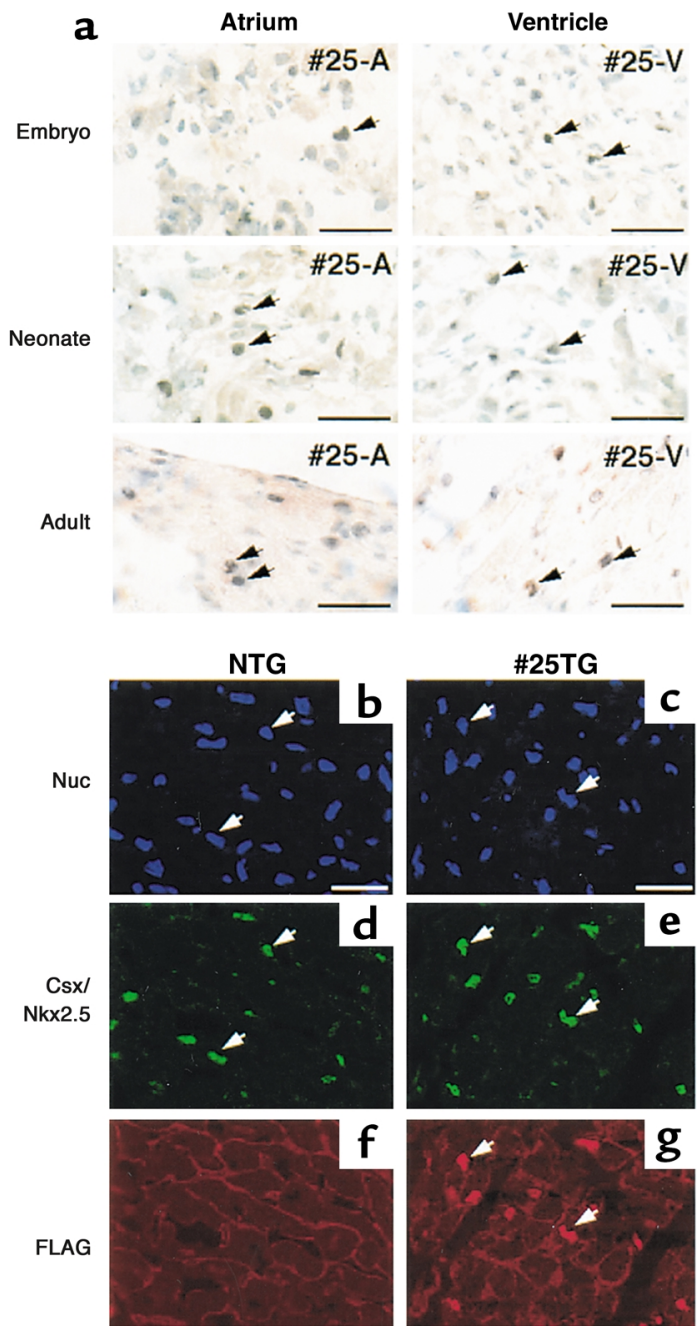

h

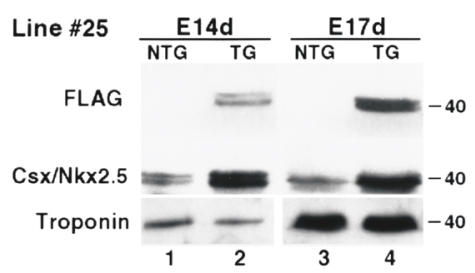

i

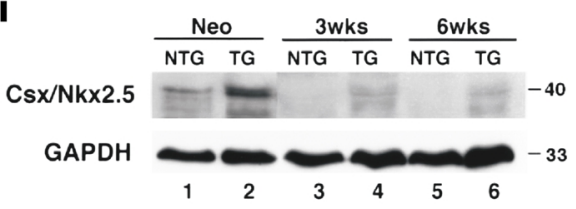

j
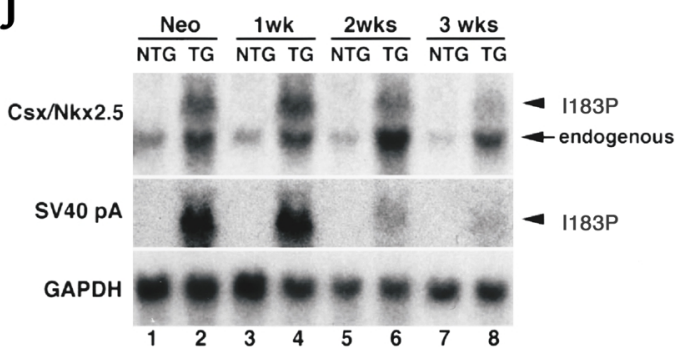

\section{Figure 7}

Expression of Csx/Nkx2.5(I183P) and endogenous Csx/ Nkx2.5 in TG mice. (a) Immunohistochemistry showed Csx/ Nkx2.5(I183P) mutant protein expression in atria and ventricle in embryonic, neonatal, and adult atria (\#25-A) and ventricles (\#25-V). Bars = 50 mm. (b-g) Adult heart from NTG (b, d, f) and TG (c, e, g) mice were coimmunostained with anti-Csx/Nkx2.5 Ab (d, e, FITC) and anti-FLAG Ab (f, $\mathbf{g}$, rhodamine). Nuclear staining was shown in Blue $(\mathbf{b}, \mathbf{c})$. Most of the FITC and rhodamine stainings in e and $\mathbf{g}$ were colocalized. Bars $=50$ mm. (h) Mutant protein expression at 14 (lane 2) and $17 \mathrm{dpc}$ (lane 4) by Western blotting using anti-FLAG pAb (upper panels) and anti-Csx/Nkx2.5 $\mathrm{mAb}$ (lower panels). In lane 2 and 4, both endogenous and mutant proteins were recognized with anti-Csx/Nkx2.5 Ab and showed approximately twofold higher Csx/ Nkx2.5 protein expression than NTG (lane 1 vs. lane 2, lane 3 vs. lane 4). (i) Western blot analysis of heart lysate from neonate, 3 and 6 weeks of NTG and TG mice with anti-Csx/Nkx2.5 mAb detected endogenous protein in NTG hearts (lanes 1, 3, 5) as well as the endogenous plus the mutant protein in TG heart (lanes 2, 4, 6). (j) Northern blot analysis of Csx/Nkx2.5 and SV40 poly A. At neonatal stage, Csx/Nkx2.5 mRNA was detected as a major single band in NTG heart (Csx/Nkx2.5, lane 1), and two bands in TG heart (lane 2). The slower migrating ban hybridized with SV40 poly A probe indicating the transcript of I183P mutant (SV40 pA, lane 2). In NTG hearts, Csx/Nkx2.5 mRNA level was downregulated after birth (compare lane 1 vs. lanes 3, 5, 7). However, the downregulation of the endogenous $\mathrm{Csx} / \mathrm{Nkx} 2.5$ was not observed in TG hearts (lanes $2,4,6,8$ ), indicating the upregulation of endogenous Csx/Nkx2.5 in TG hearts.

(Figure 8e, connexin 43, lane 2 vs. lane 4). Northern blot analysis confirmed the downregulation of connexin 43 mRNA expression in GFP-TG, but not in Ras(N17)-TG mice (Figure 8f).

We further examined cardiac connexin 43 expression in animals with heart failure due to left coronary artery ligation. In two moderate (Figure $8 \mathrm{~g}$, lane 4 and 5) and two severe heart failure mice (Figure $8 \mathrm{~g}$, lanes 6 and 7), connexin 43 expression in the noninfarcted upper ventricular septum was not significantly different compared with three sham-operated mice (Figure 8g, lanes
1-3). Thus, modest downregulation of connexin 43 expression was observed only in GFP-TG mice and not in two other models of heart failure.

Wild-type Csx/Nkx2.5 transgene causes embryonic lethality. We attempted to generate mice that overexpress wild-type $\mathrm{Csx} / \mathrm{Nkx} 2.5$ under the $\beta$-MHC promoter to examine the specificity of the phenotype observed in Csx/ Nkx2.5(I183P)TG mice. Unexpectedly, we were unable to obtain wild-type Csx/Nkx2.5 transgenic lines after screening $297 \mathrm{~F}_{0}$ mice, in contrast with I183P mutant transgene for which we obtained 6 founders out of $28 \mathrm{~F}_{0}$ mice. Upon screening of 

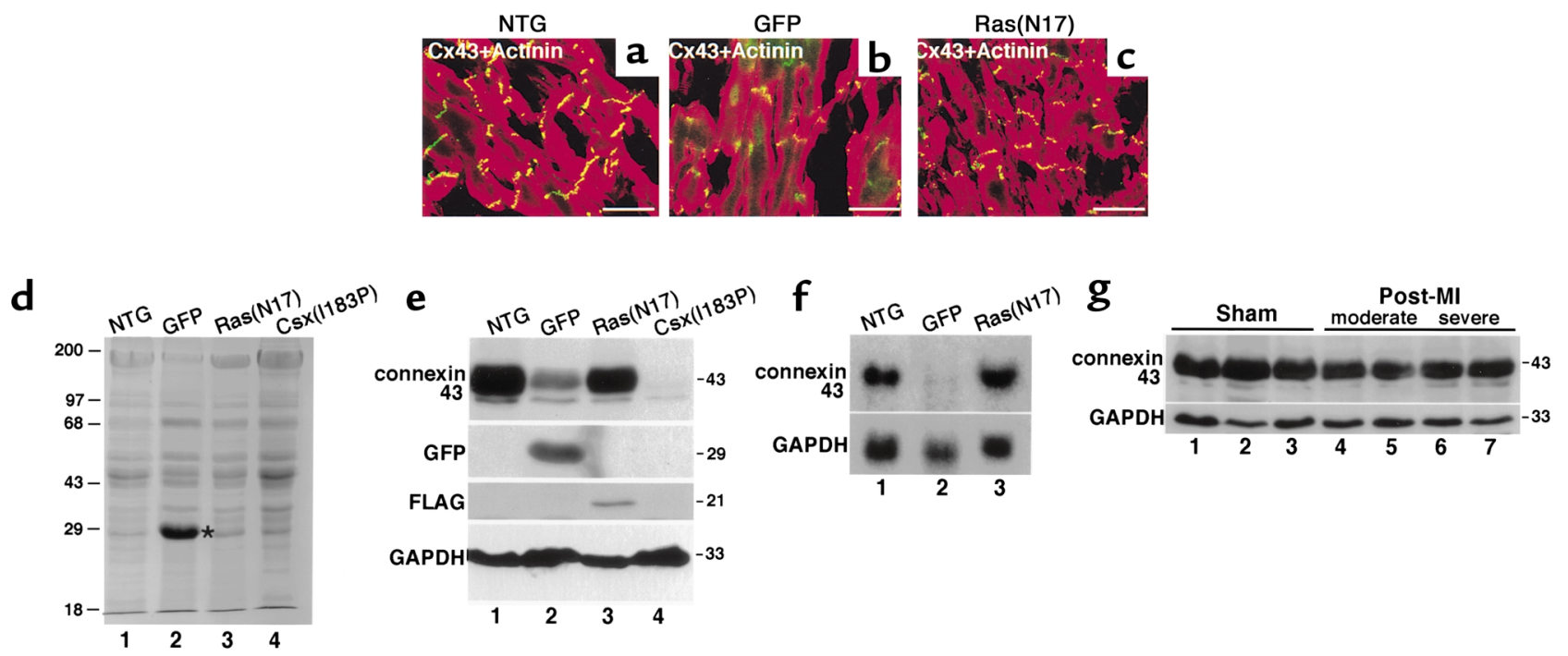

\section{Figure 8}

Connexin 43 expression in other heart failure mouse models. (a-c) Connexin 43 expression in two other heart failure TG mouse models expressing either GFP protein (b) or dominant negative H-Ras[Ras(N17)] (c) were analyzed and compared with the NTG mouse (a). Heart sections were coimmunostained for connexin 43 (FITC) and $\alpha$-actinin (rhodamine). Connexin 43 downregulation was observed in GFP-TG (b), which showed additional green fluorescence in both cytosol and nuclei of the GFP signal. Bars, $30 \mu \mathrm{m}$. (d) SDS-PAGE- and Coomassie blue-stained heart lysate from NTG (lane 1), GFP-TG (lane 2), Ras(N17)-TG (lane 3), and Csx/Nkx2.5(I183P)-TG (lane 4) mice detected high GFP expression around $29 \mathrm{kDa}$ (lane 2, marked with an asterisk). (e) Western blot analysis from these lysates revealed connexin 43 downregulation in GFP-TG (lane 2) and Csx/Nkx2.5(I183P)-TG mice (lane 4). The membrane was blotted with anti-GFP and anti-FLAG for $\operatorname{Ras}(\mathrm{N} 17)$. Csx/Nkx2.5(I183P) expression was under detection levels (data not shown). GAPDH expression is also shown. (f) Northern blot analysis from NTG (lane 1), GFP-TG (lane 2), or Ras(N17)-TG (lane 3) showed downregulation of connexin 43 mRNA in GFP-TG the mouse (lane 2). (g) Connexin 43 expression in post-myocardial infarction heart failure mice. Noninfarcted upper septum dissected from three shamoperated (lanes 1-3), two moderate (lanes 4 and 5), and two severe (lanes 6 and 7 ) heart failure mice were analyzed for connexin 43 expression. No significant differences were detected among these mice.

embryos at $14.5 \mathrm{dpc}, 5$ genotype-positive embryos among 17 embryos (29\%) were found, which is comparable to the transgene-positive ratio for Csx/ $\mathrm{Nkx2.5(I183P)-TG} \mathrm{construct} \mathrm{(21 \% ).} \mathrm{All} \mathrm{these}$ Csx/Nkx2.5(wild)-TG embryos (nos. 1, 7, 10, 13, and 14) showed mild to severe growth retardation (Figure 9a). Heart sections of the five Csx/Nkx2.5(wild)-TG embryos showed various abnormalities compared with the NTG heart (Figure 9, b and c vs. d-h). Numbers 1 (Figure 9d), 7 (Figure 9e), and 10 (Figure 9f) mice showed small ventricular cavities with thick ventricular walls associated with thick atrial walls. Numbers 13 (Figure $9 \mathrm{~g}$ ) and 14 (Figure 9h) hearts were relatively normal, but had thinner ventricular walls compared with NTG heart (Figure 9, b and c). Higher magnification of no. $1 \mathrm{Csx} / \mathrm{Nkx} 2.5$ (wild)-TG heart showed the thick atrial as well as ventricular wall compared with NTG (Figure 9, i vs. j, k vs. 1). Each embryo analyzed most likely expressed different amounts of wild-type Csx/Nkx2.5 protein.

\section{Discussion}

The NK2 class homeoprotein Csx/Nkx2.5 is among the earliest cardiogenic markers from fly to vertebrate (1-9). In this study, we generated transgenic mice expressing a putative dominant inhibitory mutant of Csx/ $\mathrm{Nkx} 2.5$ $(13,14)$ under the $\beta$-MHC promoter in order to exam- ine Csx/ $\mathrm{Nkx} 2.5$ function in the mammalian embryonic heart. Overexpression of a DNA-nonbinding mutant of $\mathrm{XNkx2.5}$ in Xenopus embryos resulted in small hearts or a complete loss of heart (13). We anticipated similar results in mice, but that was not the case. The accumulation of Csx/Nkx2.5(I183P) mutant protein in the embryo, neonate, and adult myocardium resulted in progressive and profound cardiac conduction defects and heart failure.

One possible explanation for the phenotypic difference observed in the Xenopus system and in our transgenic mice is the different experimental conditions in the different species. In Xenopus, the mutant mRNA was injected in dorsal-vegetal blastomeres of the eight-cell stage (2.25 hours after fertilization) before the endogenous $X N k \times 2.5$ transcripts were expressed (stage $13,14.75$ hours after fertilization) $(13,32)$. In the mouse, strong expression of Csx/Nkx2.5 starts around $7.5 \mathrm{dpc}$ and the $\beta$-MHC promoter, which drives Csx/Nkx2.5(I183P) mutant expression, becomes active at approximately a half day later during mouse development (around $8 \mathrm{dpc}$ ) (28).

The $\beta$-MHC promoter is reported to be downregulated shortly after birth $(15,28,29)$, but the switch from $\beta$-MHC to $\alpha$-MHC does not occur in most of the specialized conduction system (24). In addition, the reactivation of the $\beta$-MHC gene is commonly found in rodent models of heart failure (33). Therefore, heart 

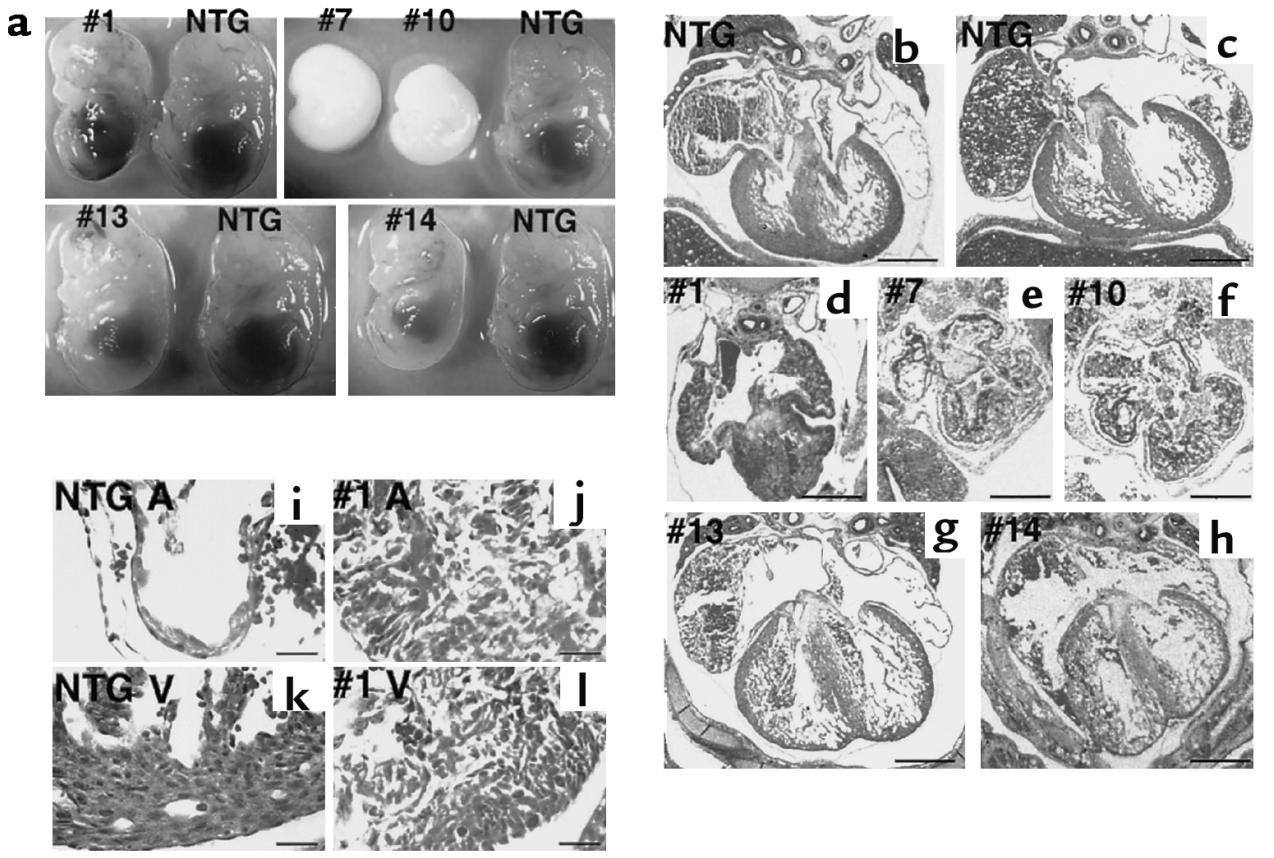

\section{Figure 9}

TG mice expressing wild-type $\mathrm{Csx} / \mathrm{Nkx2.5}$ showed embryonic lethal phenotype with various heart defects. (a) $\mathrm{F}_{0}$ embryos of wild-type Csx/Nkx2.5 TG mice at $14.5 \mathrm{dpc}$. Five TG-positive (nos. 1, 7, 10, 13, and 14) and control NTG embryos are compared. Number 1 embryo showed generalized hemorrhage, and no. 7 and no. 10 embryos were almost absorbed. Numbers 13 and 14 embryos were relatively normal, except they had slight growth retardation compared with NTG embryos. (b-h) Hematoxylin/eosin-stained sections of the embryos. Compared to the two NTG hearts (b and c), no. 1 (d), no. 7 (e), and no. 10 (f) embryos showed thick myocardium accompanied with small atrial and ventricular cavity. Numbers $13(\mathbf{g})$ and $14(\mathbf{h})$ embryos showed relatively normal heart formation, but the ventricular wall was thinner than the NTG heart. Bars, $0.4 \mathrm{~mm}$. (i-I) Higher magnification of NTG (i and $\mathbf{k}$ ) and no. 1 TG mouse hearts (j and $\mathbf{I})$. NTG heart clearly showed differentiated cardiomyocytes in atria (i) and ventricle ( $\mathbf{k})$. In the TG atria (j) and the TG ventricle (I), cardiomyocytes did contact each other. Bars, $50 \mu \mathrm{m}$.

failure in Csx/Nkx2.5(I183P)-TG mice may directly or indirectly contribute to the continuous activation of the transgenic $\beta$-MHC promoter.

Conduction defects and downregulation of gap junction protein connexins. Myocardial electrical conduction depends on intercellular transfer of current at gap junctions. Gap junctions are clusters of membrane channels formed by the proteins encoded by a multigene connexin family (34). At least four connexin gene products have been identified in the mammalian heart (connexin $37,40,43$, and 45) $(23,35)$. Among these, connexin 43 is the major component of gap junctions both in the atrium and ventricle after birth, in contrast connexin 40 expressed specifically in the atrium and the conduction system (23-26) (see Figures 4 and 5).

Connexin 43 homozygous null mice survived to birth, but died shortly after birth due to an obstruction of the subpulmonary outflow tract (36). Heterozygous mice that express $50 \%$ reduced levels of connexin 43 protein had slowed ventricular conduction, but had normal sinus node, AV node, or atrial conduction $(37,38)$. In contrast, connexin 40 homozygous deficient mice survived and showed conduction defects, such as first-degree AV block with associated bundle branch block $(25,26)$. Therefore, markedly decreased connexin 40 and 43 expression in the
Csx/Nkx2.5(I183P)-TG heart is likely to have contributed to the profound conduction defects in Csx/Nkx2.5(I183P)-TG mice.

Connexins may be direct or indirect downstream targets of $\mathrm{Csx} / \mathrm{Nkx2.5}$. Indeed, multiple consensus binding sites for Csx/Nkx2.5 (TNAAGTG) (39) are found in the connexin 40 and connexin 43 promoters $(40,41)$. It is an open question why these connexins were downregulated only after the neonatal period. Connexin expression in the heart may be regulated by different mechanisms before and after birth. It is possible that the I183P mutant acts on connexin gene enhancers after birth, either directly or indirectly by regulating the expression of major transactivators. It is also possible that cofactors of Csx/ $\mathrm{Nkx} 2.5$ that are essential for connexin 40 and 43 expression after birth are sequestered by the I183P mutant.

Connexin downregulation and heart failure. In Csx/Nkx2.5(I183P)-TG (line no. 25) mice, connexin 40 and 43 proteins were markedly decreased by 3 weeks of age, and conduction defects were observed as early as 2 weeks of age. The pathological changes and the increase in heart weight/body weight occurred after 3 weeks of age, suggesting that conduction defects started before apparent heart failure. Certainly, conduction defects aggravate heart failure, which might be induced by other mechanisms in 
Csx/Nkx2.5(I183P)-TG mice, and heart failure further decreases gap junction function, as reported previously (42-44).

However, heart failure alone seems insufficient to decrease connexin 43 expression by more than $90 \%$ as seen in Csx/Nkx2.5(I183P)-TG mice. Downregulation of connexin 43 expression was not observed in two other models of heart failure: dominant negative Ras(N17)-TG (T. Shioi and S. Izumo, unpublished data) or postmyocardial infarction. Although GFP-TG mice (16) showed moderate downregulation of connexin 43 , a very high level of expression of GFP protein (more than that of myosin) was insufficient to decrease connexin 43 expression to the extent observed in Csx/Nkx2.5(I183P)-TG mice (Figure 8, $\mathrm{d}$ and e). Of note, we used $\alpha$-MHC promoter to express GFP protein, therefore the findings that connexin 43 expression was not as severely affected in GFP-TG mice may relate to the transgenic promoter used.

Very recently, Gutstein et al. reported cardiac-restricted inactivation of connexin 43 (45). These mice showed slowed ventricular conduction and spontaneous ventricular arrhythmias resulting in sudden cardiac death, but did not show heart failure. Furthermore, connexin 40 homozygous-deficient mice developed conduction defects but not heart failure $(25,26)$. This suggests that downregulation of connexins are not sufficient to cause heart failure. Thus heart failure observed in Csx/Nkx2.5(I183P)-TG is likely due to additional effects of the mutant protein.

Mouse model for AV-conduction defects and heart failure. As described above, we expected that expression of Csx/ $\mathrm{Nkx} 2.5(\mathrm{I} 183 \mathrm{P})$ mutant protein would result in a small heart similar to Xenopus embryos overexpressing a DNA-nonbinding mutant of XNkx2.5 (13). We also anticipated a larger heart with cardiomyocyte hyperplasia in Csx/Nkx2.5(wild)-TG mice as seen in Xenopus and zebrafish embryos $(7,32)$. Since we could not generate transgenic lines of Csx/ Nkx2.5(wild)-TG, it is difficult to examine the mechanism of the heart defects in these mice. However, we can conclude that overexpression of wild-type $\mathrm{Csx} / \mathrm{Nkx} 2.5$ has more severe effects on embryonic heart formation than Csx/Nkx2.5(I183P) mutant protein. It is possible the phenotype of Csx/Nkx2.5(I183P)-TG is a hypomorphic gain-of-function effect. We found that the expression of the endogenous Csx/Nkx2.5 mRNA is elevated by two- to fourfold in Csx/Nkx2.5(I183P)-TG hearts, but not in GFP-TG or Ras(N17)-TG (data not shown). It is also possible that the upregulation of endogenous $\mathrm{Csx} / \mathrm{Nkx} 2.5$ may have contributed to the phenotype of Csx/Nkx2.5(I183P)-TG.

The phenotype observed in Csx/Nkx2.5(I183P)-TG mice is reminiscent of that observed in subset of patients with CSX/NKX2.5 HD mutations: progressive and advanced $\mathrm{AV}$ conduction defects and left-ventricular dysfunction after birth (10-12). Of note, the Csx/ $\mathrm{Nkx2.5(I183P)-TG} \mathrm{mice} \mathrm{did} \mathrm{not} \mathrm{show} \mathrm{apparent} \mathrm{anatom-}$ ical anomalies, such as atrial septal defect or ventricular septal defect observed in human patients. This is most likely due to the different spatio-temporal expression of the mutant protein in Csx/Nkx2.5(I183P)-TG mice. Further analysis of patients with CSX/NKX2.5 mutations, as well as the creation of the "knock-in" mouse that harbors the heterozygous point mutant allele of Csx/ $\mathrm{Nkx} 2.5$, is necessary to understand the mechanism of congenital heart disease associated with CSX/NKX2.5 mutations. In summary, we created a new animal model for conduction abnormalities and heart failure by Csx/ $\mathrm{Nkx} 2.5$ mutant protein expression. Since Csx/Nkx2.5 is a critical transcription factor for the formation and maturation of the heart, analysis of these mice will aid in the elucidation of the process of heart formation and maturation, especially of gap junctions and the conduction system.

\section{Acknowledgments}

We thank E.O. Weinberg for critical reading of the manuscript and valuable suggestions; S. Ngoy for mouse surgery; M.M. Vargas for assistance in ECG studies; S. Hagan, R. Mitchell, D. Brown, and S. White for histology studies; J. Robbins for $\alpha$ - and $\beta$-MHC promoter constructs; and M.R. Deans, A.M. Simon for connexin probes and connexin 40 genomic DNA. This work was supported by the American Heart Association (AHA) Massachusetts Affiliate Fellowship, AHA Massachusetts Affiliate Beginning-Grant-in-Aid, Charles H. Hood Foundation (H. Kasahara), and SCOR in Congenital Heart Disease grant from the NIH (P50HL61036; S. Izumo and C.I. Berul).

1. Bodmer, R. 1993. The gene tinman is required for specification of the heart and visceral muscles in Drosophila. Development. 118:719-729.

2. Azpiazu, N., and Frasch, M. 1993. Tinman and bagpipe: two homeo box genes that determine cell fates in the dorsal mesoderm of Drosophila. Genes Dev. 7:1325-1340.

3. Lints, T.J., Parsons, L.M., Hartley, L., Lyons, I., and Harvey, R.P. 1993. $N k x-2.5$ : a novel murine homeobox gene expressed in early heart progenitor cells and their myogenic descendants. Development. 119:419-431.

4. Komuro, I., and Izumo, S. 1993. Csx: a murine homeobox-containing gene specifically expressed in the developing heart. Proc. Natl. Acad. Sci. USA. 90:8145-8149.

5. Tonissen, K.F., Drysdale, T.A., Lints, T.J., Harvey, R.P., and Krieg, P.A. 1994. XNkx-2.5, a Xenopus gene related to $N k x-2.5$ and tinman: evidence for a conserved role in cardiac development. Dev. Biol. 162:325-328.

6. Schultheiss, T.M., Xydas, S., and Lassar, A.B. 1995. Induction of avian cardiac myogenesis by anterior endoderm. Development. 121:4203-4214.

7. Chen, J.N., and Fishman, M.C. 1996. Zebrafish tinman homolog demarcates the heart field and initiates myocardial differentiation. Development. 122:3809-3816.

8. Turbay, D., Wechsler, S.B., Blanchard, K.M., and Izumo, S. 1996. Molecular cloning, chromosomal mapping, and characterization of the human cardiac-specific homeobox gene $h$ Csx. Mol. Med. 2:86-96.

9. Shiojima, I., et al. 1996. Molecular cloning and characterization of human cardiac homeobox gene CSX1. Circ. Res. 79:920-929.

10. Schott, J.J., et al. 1998. Congenital heart disease caused by mutations in the transcription factor NKX2-5. Science. 281:108-111.

11. Benson, W., et al. 1999. Mutations in the cardiac transcription factor Nkx2-5 affect diverse cardiac developmental pathways. J. Clin. Invest. 104:1567-1573.

12. Kasahara, H., et al. 2000. Loss of function and inhibitory effects of human CSX/NKX2.5 homeoprotein mutations associated with congenital heart disease. J. Clin. Invest. 106:299-308.

13. Grow, M.W., and Krieg, P.A. 1998. Tinman function is essential for vertebrate heart development: elimination of cardiac differentiation by dominant inhibitory mutants of the tinman-related genes, $X N k \times 2-3$ and XNkx2-5. Dev. Biol. 204:187-196.

14. Kasahara, H., et al. 2001. Characterization of homo- and heterodimerization of cardiac Csx/Nkx2.5 homeoprotein. J. Biol. Chem. 20:4570-4580. 
15. Rindt, H., Gulick, J., Knotts, S., Neumann, J., and Robbins, J. 1993. In vivo analysis of the murine beta-myosin heavy chain gene promoter. J. Biol. Chem. 268:5332-5338.

16. Huang, W.Y., Aramburu, J., Douglas, P.S., and Izumo, S. 2000. Transgenic expression of green fluorescence protein can cause dilated cardiomyopathy. Nat. Med. 6:482-483.

17. Gulick, J., Subramaniam, A., Neumann, J., and Robbins, J. 1991. Isolation and characterization of the mouse cardiac myosin heavy chain genes. J. Biol. Chem. 266:9180-9185.

18. Kasahara, H., Bartunkova, S., Schinke, M., Tanaka, M., and Izumo, S. 1998. Cardiac and extra-cardiac expression of Csx/Nkx2.5 homeodomain protein. Circ. Res. 82:936-946.

19. Manning, W.J., Wei, J.Y., Katz, S.E., Litwin, S.E., and Douglas, P.S. 1994. In vivo assessment of LV mass in mice using high-frequency cardiac ultrasound: necropsy validation. Am. J. Physiol. 266:H1672-H1675.

20. Berul, C.I., Aronovitz, M.J., Wang, P.J., and Mendelsohn, M.E. 1996. In vivo cardiac electrophysiology studies in the mouse. Circulation. 94:2641-2648.

21. Gehrmann, J., and Berul, C.I. 2000. Cardiac electrophysiology in genetically engineered mice. J. Cardiovasc. Electrophysiol. 11:354-368.

22. Mitchell, G.F., Jeron, A., and Koren, G. 1998. Measurement of heart rate and Q-T interval in the conscious mouse. Am. J. Physiol. 274:H747-H751.

23. Gros, D.B., and Jongsma, H.J. 1996. Connexins in mammalian heart function. Bioessays. 18:719-730.

24. Moorman, A.F., de Jong, F., Denyn, M.M., and Lamers, W.H. 1998. Development of the cardiac conduction system. Circ. Res. 82:629-644.

25. Simon, A.M., Goodenough, D.A., and Paul, D.L. 1998. Mice lacking connexin 40 have cardiac conduction abnormalities characteristic of atrioventricular block and bundle branch block. Curr. Biol. 8:295-298.

26. Kirchhoff, S., et al. 1998. Reduced cardiac conduction velocity and predisposition to arrhythmias in connexin40-deficient mice. Curr. Biol. 8:299-302.

27. Severs, N.J. 2000. The cardiac muscle cell. Bioessays. 22:188-199.

28. Lyons, G.E., Schiaffino, S., Sassoon, D., Barton, P., and Buckingham, M. 1990. Developmental regulation of myosin gene expression in mouse cardiac muscle. J. Cell. Biol. 111:2427-2436.

29. Robbins, J. 1997. Altering cardiac function via transgenesis, a nuts and bolts approach. Trends Cardiovasc. Med. 7:185-191.

30. Kasahara, H., and Izumo, S. 1999. Identification of the in vivo casein kinase II phosphorylation site within the homeodomain of the cardiac tissue-specifying homeobox gene product Csx/Nkx2.5. Mol. Cell. Biol. 19:526-536.

31. Ng, W.A., Grupp, I.L., Subramaniam, A., and Robbins, J. 1991. Cardiac myosin heavy chain mRNA expression and myocardial function in the mouse heart. Circ. Res. 68:1742-1750.

32. Cleaver, O.B., Patterson, K.D., and Krieg, P.A. 1996. Overexpression of the tinman-related genes $X N k x-2.5$ and $X N k x-2.3$ in Xenopus embryos results in myocardial hyperplasia. Development. 122:3549-3556.

33. Colbert, M.C., et al. 1997. Cardiac compartment-specific overexpression of a modified retinoic acid receptor produces dilated cardiomyopathy and congestive heart failure in transgenic mice. J. Clin. Invest. 100:1958-1968.

34. Simon, A.M., and Goodenough, D.A. 1998. Diverse functions of vertebrate gap junctions. Trends Cell Biol. 8:477-483.

35. Saffitz, J.E., Laing, J.G., and Yamada, K.A. 2000. Connexin expression and turnover: implications for cardiac excitability. Circ. Res. 86:723-728.

36. Reaume, A.G., et al. 1995. Cardiac malformation in neonatal mice lacking connexin43. Science. 267:1831-1834.

37. Guerrero, P.A., et al. 1997. Slow ventricular conduction in mice heterozygous for a connexin43 null mutation. J. Clin. Invest. 99:1991-1998.

38. Thomas, S.A., et al. 1998. Disparate effects of deficient expression of connexin 43 on atrial and ventricular conduction: evidence for chamber-specific molecular determinants of conduction. Circulation. 97:686-691.

39. Chen, C.Y., and Schwartz, R.J. 1995. Identification of novel DNA binding targets and regulatory domains of a murine tinman homeodomain factor, nkx-2.5. J. Biol. Chem. 270:15628-15633.

40. Chen, Z.Q., Lefebvre, D., Bai, X.H., Reaume, A., Rossant, J., and Lye, S.J. 1995. Identification of two regulatory elements within the promoter region of the mouse connexin 43 gene. J. Biol. Chem. 270:3863-3868.

41. Seul, K.H., Tadros, P.N., and Beyer, E.C. 1997. Mouse connexin40: gene structure and promoter analysis. Genomics. 46:120-126.

42. Severs, N.J. 1994. Gap junction alterations in the failing heart. Eur. Heart J. 15(Suppl. D):53-57.

43. Wang, X., and Gerdes, A.M. 1999. Chronic pressure overload cardiac hypertrophy and failure in guinea pigs. III. Intercalated disc remodeling. J. Mol. Cell. Cardiol. 31:333-343.

44. Toyofuku, T., et al. 1999. Functional role of $\mathrm{c}$-Src in gap junctions of the cardiomyopathic heart. Circ. Res. 85:672-681.

45. Gutstein, D.E., et al. 2001. Conduction slowing and sudden arrhythmic death in mice with cardiac-restricted inactivation of connexin 43. Circ. Res. 88:333-339. 